\title{
Hepatic infarction after transcatheter arterial chemoembolization and radiofrequency ablation therapy for hepatocellular carcinoma
}

Toru Ishikawa*, Michitaka Imai, Takashi Owaki, Marina Okoshi, Hiroki Sato, Yujiro Nozawa, Tomoe Sano, Akito Iwanaga, Keiichi Seki, Terasu Honma and Toshiaki Yoshida

Department of Gastroenterology and Hepatology, Saiseikai Niigata Daini Hospital, Niigata, Japan

A 76-year-old male with hepatocellular carcinoma (HCC) recurrence and liver cirrhosis caused by hepatitis $\mathrm{C}$ virus infection was admitted to our hospital for further examination and treatment. He had undergone transcatheter arterial chemo-embolization (TACE) and radiofrequency ablation (RFA) for recurrent HCC in segment 3. After 1 month, he complained of continuous abdominal pain and fever up. His serum aspartate aminotransferase (AST) was $573 \mathrm{IU} / \mathrm{L}$ (normal, 13-30 IU/L), alanine aminotransferase (ALT) was $456 \mathrm{IU} / \mathrm{L}$ (normal, $10-42 \mathrm{U} / \mathrm{L}$ ), lactate dehydrogenase (LDH) was $623 \mathrm{IU} / \mathrm{L}$ (normal, 124$222 \mathrm{IU} / \mathrm{L}$ ), and $\mathrm{C}$ reactive protein was $15.37 \mathrm{mg} / \mathrm{dL}$ (normal, $<0.3 \mathrm{mg} / \mathrm{dL}$ ).

Abdominal computed tomography (CT) imaging unexpectedly showed a large unenhanced area that was representative of infarcted liver parenchyma involving the entire left lateral sector, along with obliteration of the left portal vein branches (Figure 1). We diagnosed hepatic infarction, and treated conservative therapy including antibiotics. Four months after RFA and TACE, the hepatic infarction had decreased in size on CT imaging and had atrophy of left lobe (Figure 2).

Hepatic infarction is diagnosed by the presence of a welldemarcated, low-attenuated, peripheral, wedge-shaped area on contrast CT imaging [1]. Generally, the blood supply system of the liver is composed of portal vein, which provides two-thirds of the blood

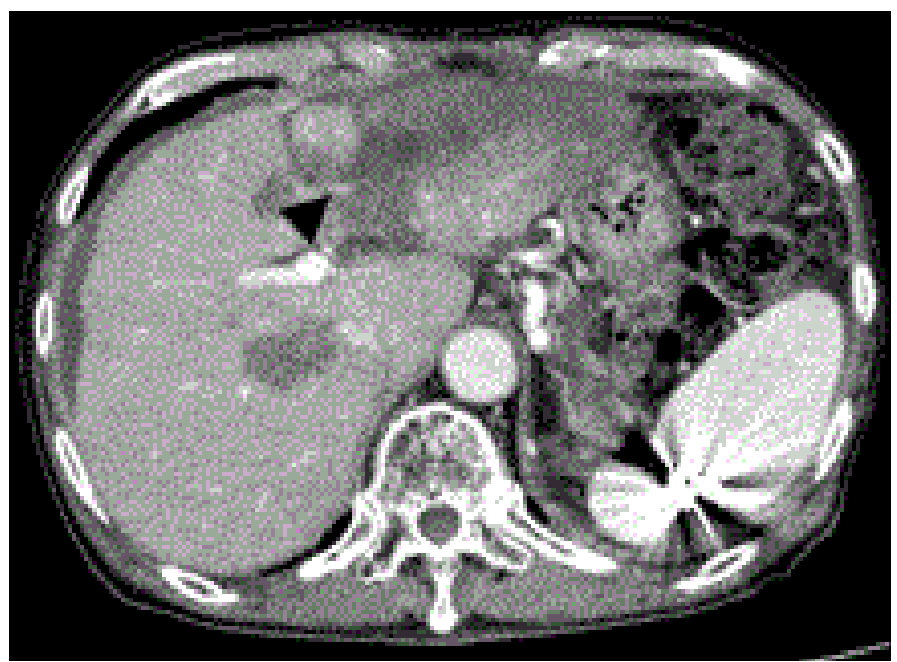

Figure 1. Abdominal computed tomography imaging showed a large unenhanced area (arrow head) that was representative of infarcted liver parenchyma involving the entire left lateral sector, along with obliteration of the left portal vein branches.

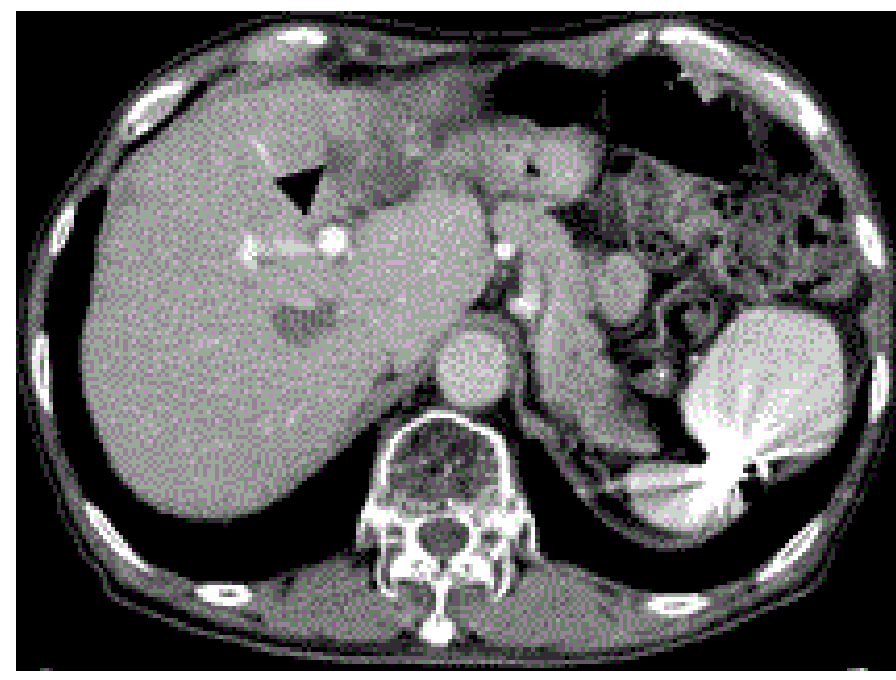

Figure 2. Abdominal computed tomography imaging showed that the hepatic infarction had decreased in size (arrow head) 4 months after RFA and TACE.

supply, and the hepatic artery, which provides the remaining one-third of the blood supply [2]. Unlike findings in other major abdominal organs, infarction is relatively rare in the liver. In humans, the rarity of hepatic infarction can be explained by the dual blood supply from the hepatic artery and portal vein, and by the extensive collateral pathways [3-7].

Interventional procedures such as arterial embolization [8] and/ or radiofrequency ablation (RFA) [1] are one of the causes of hepatic infarction.

However, sporadic cases of hepatic infarction following interventional procedures have been reported and some have been critical $[9,10]$.

Caution is warranted when RFA after TACE are planned to be performed at a site near a large vessel, particularly in patients with limited liver reserve.

Correspondence to: Toru Ishikawa, M.D, Department of Gastroenterology and Hepatology, Saiseikai Niigata Daini Hospital, Teraji 280-7, Niigata 950-1104, Japan, Tel: 81-25-233-6161; Fax: 81-25-233-8880; E-mail: toruishi@ngt.saiseikai.or.jp

Received: March 30, 2018; Accepted: April 16, 2018; Published: April 19, 2018 


\section{References}

1. Kim YS, Rhim H, Lim HK, Choi D, Lee WJ, Kim SH (2007) Hepatic infarction after radiofrequency ablation of hepatocellular carcinoma with an internal cooled electrode. J Vasc Interv Radiol 18: 1126-1133. [Crossref]

2. Bauer W, Dale HH, Poulsson LT, Richards DW (1932) The control of circulation through the liver. J Physiol 74: 343-375. [Crossref]

3. Clarke JS (1955) Hepatic necrosis following celiac artery ligation during gastric resection in man. Arch Surg 71: 171-177. [Crossref]

4. Michels NA (1966) Newer anatomy of liver and its variant blood supply and collateral circulation. Am J Surg 112: 337-347. [Crossref]

5. Kanter DM (1965) Hepatic infarction. Arch Intern Med 115: 479-481. [Crossref]
6. Ternberg JL, Butcher HR Jr (1965) Blood-flow relation between hepatic artery and portal vein. Science 150: 1030-1031. [Crossref]

7. Redman HC, Reuter SR (1970) Arterial collaterals in the liver hilus. Radiology 94 575-579. [Crossref]

8. Gates J, Hartnell GG, Stuart KE and Clouse ME (1999) Chemoembolization of hepatic neoplasms: Safety, complications, and when to worry. Radiographics 19: 399-414 [Crossref]

9. Miller FJ Jr, Mineau DE (1983) Transcatheter arterial embolization-major complications and their prevention. Cardiovasc Intervent Radiol 6: 141-149. [Crossref]

10. Trojanowski JQ, Harrist TJ, Athanasoulis CA Greenfield AJ (1980) Hepatic and splenic infarctions: Complications of therapeutic transcatheter embolization. Am J Surg 139: 272-277. [Crossref]

Copyright: (C2018 Ishikawa T. This is an open-access article distributed under the terms of the Creative Commons Attribution License, which permits unrestricted use, distribution, and reproduction in any medium, provided the original author and source are credited. 